International Electronic Journal of Geometry

Volume 7 No. 1 Pp. 1-3 (2014) CIEJG

\title{
IN MEMORY OF FRANKI DILLEN
}

\author{
BANG-YEN CHEN, JOERI VAN DER VEKEN, AND LUC VRANCKEN
}

Franki Dillen was born in Balen (Belgium) on March 15, 1963. After studying at the high school Sint-Jan Berchmanscollege in Mol until 1981, he went to study mathematics at the Katholieke Universiteit Leuven, where he finished his undergraduate studies in 1985. At that time, he had already obtained several original results. In his final year work he studied curvature conditions for hypersurfaces in Euclidean space involving the Weyl projective curvature tensor. Doing so, he obtained a new characterisation of the hypercatenoids. This lead to his first publication in an international scientific journal. This work was done under the direction of Prof. dr. Leopold Verstraelen. At that time, it was common that during the geometry seminar a book was studied in detail, both by the final year undergraduates and the PhD students in differential geometry. As the first author at that time had introduced the notion of finite type submanifolds and just finished his book "Total mean curvature and submanifolds of finite type" (World Scientific Publishing, Singapore, 1984) on that subject, the choice fell on this book in Franki's final year. In his seminar, Franki had to present the classification of two-type curves. As he was not convinced by the arguments in the book, he presented a counterexample to the statement of the theorem in the book followed by a corrected classification theorem. To some extent this illustrates Franki's thoroughness: once you could convince Franki that a certain mathematical argument is correct you could be absolutely certain that it was indeed correct. Naturally, these results were also published. During his undergraduate studies he received top marks at the end of every year. After his undergraduate studies, he continued working in differential geometry in order to obtain a $\mathrm{PhD}$. Like for his undergraduate work, his advisor was Leopold Verstraelen. He obtained his PhD degree on December 10, 1988, again with the greatest distinction.

Before and after his PhD, Franki visited the first author several times at Michigan State University. This was the starting point of a very fruitful cooperation on a variety of themes in submanifold theory leading up to this point to 29 joint publications. The third author got to know Franki at the beginning of 1986. At that time the third author was a final year undergraduate student, while Franki had just started working on his $\mathrm{PhD}$. This was also the starting point of an extremely fruitful cooperation between Franki and the third author, leading up to 68 joint publications to this point. Franki started lecturing at the Katholieke Universiteit Leuven from 1992 where he was promoted to professor a few years later. This is how the second author first met Franki in 2000: although he was a first year engineering student, he attended Franki's geometry course for first year mathematics students. Franki's 
inspiring course and approach made him appreciate the beauty of mathematics even more, which led to a career switch and a graduation in mathematics. $\mathrm{He}$ made a $\mathrm{PhD}$ in differential geometry under the supervision of Franki and now has the difficult task to replace Franki as the head of the Geometry Section of KU Leuven. Indeed, Franki was the head of the KU Leuven Geometry Section until he deceased on April 17, 2013.

Franki's main topic of research was the study of submanifolds. His contributions include both global and local results, centered around submanifolds of spheres (in particular, but not only, the nearly Kaehler 6 -sphere), parallel and semi-parallel submanifolds, affine differential geometry, Lagrangian submanifolds, finite type submanifolds, submanifolds of product spaces,... His broad interest is also illustrated by the fact that throughout the years he collaborated with 56 different mathematicians. He was not only good in doing mathematics by himself and in collaboration with other mathematicians, he was also very good at motivating young people to start doing research in differential geometry. As such it is no surprise that he was an advisor of many $\mathrm{PhD}$ theses. Apart from the second author, his students include Johan Fastenakels, Wendy Goemans, Bahaa Eldin Abdalla, Lu Ying, Wijarn Sodsiri, Gerd Verbouwe, Daniel Kowalczyk, Ana Irina Nistor and Kristof Schoels.

People will no doubt also remember him for his lectures at conferences and the organisation of workshops, both of which already started at a very young age. He gave his first lecture at a small workshop at the Max Planck Institute in Bonn in 1986 during his first year as a PhD student. The two other speakers at this workshop were K. Nomizu and U. Pinkall. This was quickly followed by lectures at conferences at the CIRM (Centre International de Rencontre Mathématiques) in Luminy, in Avignon, in Leeds, in Berlin and at the conference center in Oberwolfach. Starting from 1991 he became also one of the organisers of a series of conferences organised under the name PADGE (Pure and Applied Differential Geometry) in Leuven and Brussels. The name, cleverly referring the the concept of a patch in differential geometry, as well as the accompanying logo, were Franki's ideas, but that is another story. Even though Franki was on paper only one of the organisers, in practice he did most of the work, which made this series very successful. The last conference he organised, despite of his advancing illness, was PADGE 2012 in Leuven, at the end of August 2012. Many of the participants expressed to us their admiration for the energy and strength that he showed in this organisation. Throughout his career, he also continued participating and lecturing at international conferences worldwide. It is remarkable that during the last year of his life he still attended a $\mathrm{PhD}$ jury in Berlin, organised the above mentioned conference in Leuven, and attended conferences in Bedlewo (Poland) and Zlatibor (Serbia).

Franki Dillen was an extraordinary gifted and dedicated mathematician as well as a good personal friend of all three of the authors. As is shown by the many messages of condolences that have reached the KU Leuven Geometry Section, he was regarded extremely warmly by many friends and widely respected as a wise and knowledgeable colleague with a fine sense of humour. He will be greatly missed by the entire mathematical community. Franki is survived by his wife Monique and his daughters Ute and Anke. 
Department of Mathematics, Michigan State University, East Lansing, Michigan 48824-1027, U.S.A.

E-mail address: bychen@math.msu.edu

KU Leuven, Department of Mathematics, Celestijnenlaan 200B - Box 2400, 3001 LeuVEN, BELGIUM

E-mail address: joeri.vanderveken@wis.kuleuven.be

LAmaV, Université de Valenciennes, Campus du Mont Houy, 59313 Valenciennes Cedex 9, France

E-mail address: luc.vrancken@univ-valenciennes.fr 